\title{
Personal or Interpersonal Construal of Happiness: A Cultural Psychological Perspective
}

\author{
Yukiko Uchida $\cdot$ Yuji Ogihara
}

\begin{abstract}
Cultural psychological research reveals considerable variation in how people construe happiness and experience subjective wellbeing. This paper identified substantial cultural differences in (1) meanings of happiness, (2) predictors of happiness, and (3) how social changes such as globalization are related to happiness. In European-American cultural contexts, happiness is construed as including experience of a highly desirable and positive emotional state defined in terms of a high arousal state such as excitement and a sense of personal achievement. Moreover, individual happiness is best predicted by personal goal attainment and high selfesteem or self-efficacy. In contrast, in East Asian cultural contexts (i.e., those found in Japan), happiness is construed as including experience of both positive and negative emotional state. Happiness is defined in terms of experiencing a low arousal state such as calmness and interpersonal connectedness and harmony. Furthermore, individual happiness is best predicted by relationship harmony and emotional support from others. While people maintain traditional cultural norms, some societies and organizations are under pressure from globalization and this might affect happiness. We examined how cultural change affects wellbeing, especially focusing on current Japanese contexts where individuals have experienced an increasing shift toward individualism and have experienced a large national disaster. Cultural psychological perspectives regarding happiness provide important contributions to psychological science and society at large.
\end{abstract}

Keywords: cultural construal of happiness, culture, happiness, achievement orientation, relationship orientation, individualism

\section{Subjective wellbeing and "cultural construal of happiness"}

What are the most important factors when evaluating our happiness? Several aspects of our experience are related to happiness, such as family, jobs, friendships, recreation, education and environment. Among these factors, that which is most important for the happiness of a particular individual can vary, given that happiness is a subjective state; what constitutes 'happiness' can be different for different individuals. For example, some people might define happiness in terms of their economic situation, while some might focus more on interpersonal relationships. Likewise, some might seek happiness through job achievement, while others seek happiness through positive relationships with others.

In addition to individual differences, there are also sizable cross-cultural differences in defining happiness. For the current paper, we define this kind of lay theory (lay definition) of happiness as being "cultural construal of happiness." We use this definition given that theories of happiness are shared within a culture and constructed through socio-cultural experiences, 
such as education (e.g., by parents and schools) and exposure to cultural products (e.g., television, newspapers, books, and so on).

Cultural psychology investigates psychological processes (i.e., cognition, emotion, and motivation) under the assumption that these processes are socio-culturally constructed (Bruner, 1990; Kitayama, Duffy, \& Uchida, 2007; Markus \& Kitayama, 1991; Shweder, 1991). This perspective is different from traditional psychological studies, which define psychological phenomena as universal entities. Rather, as Shweder (1991) suggested that culture and psyche make each other up, cultural psychology assumes that the human mind is designed to be socioculturally constructed. From this perspective, culture is defined as a set of symbolic resources, such as social practices, cultural mandates, and institutions, which are shared and historically transmitted within a community (Adams \& Markus, 2004; Kitayama et al., 2007; Kitayama, Park, Sevincer, Karasawa, \& Uskul, 2009).

We will review cross-cultural evidence revealing differences in (1) meanings of happiness, (2) predictors of happiness, and (3) how social change, such as the pressure of globalization and the impact of a natural disaster, affects happiness. We will examine the third point by focusing on the case of Japan.

\section{Why do we need to know the cultural construal of happiness?}

There is a growing body of recent research on happiness. The OECD (Organization for Economic Cooperation and Development), as well as certain countries, has attempted to measure subjective wellbeing and happiness. This, in part, is due to national and societal shifts in goals related to economic satisfaction toward subjective life satisfaction. This trend is related to declines in economic development among many industrialized societies. Economists have pointed out that both GDP and per capita GDP do not fully predict subjective wellbeing, as once suggested by the Easterlin paradox (Easterlin, 1973). On the one hand, economic growth supports life quality and increases opportunities for individual decision-making and free choice (Fisher \& Boer, 2011). On the other hand, economic growth invites stress for individuals and difficulty with environmental sustainability. Therefore, indices of economic growth are not sufficient for the measurement of physiological and psychological wellbeing within nations, especially when we try to obtain implications for policy makers.

Recent scientific research on subjective wellbeing and happiness (i.e., Diener \& Suh, 2000; Oishi, 2012) has shown that several societies have adopted psychological factors such as wellbeing, happiness, and life satisfaction as indicators of national success. The OECD published a report titled "How's Life" in 2011. This initiative was based on research into 11 aspects of life that are supposed to contribute to the wellbeing of people around the world. The OECD attempted to develop a standardized measure of subjective wellbeing that could be used for policy design and evaluation across several nations.

Approaches that take greater account of indigenous factors have also emerged. Among these, Bhutan's GNH (Gross National Happiness) Index attracted attention both from industrialized and developing countries, since the happiness of Bhutanese individuals is quite high given their economic situation. The GNH Index contains multidimensional measurements that reflect Bhutan's cultural and religious ideas and orientations. Measurements are related not only to subjective wellbeing and happiness but also to more collective and societal factors, such as community vitality, ecological resilience, and good governance (Center for Bhutan Studies, 2012). 
While the OECD's approach is more widespread and attempts to compare each society in order to investigate which aspects contribute to "happier" societies, the approaches employed such as in Bhutan also attempt to investigate specific factors important in predicting happiness within each society, based on their own cultural environment. In both cases (cross-cultural comparisons and indigenous investigations), we should consider cultural concepts of happiness, given that subjective evaluations of happiness are mostly influenced by cultural meanings and values within each nation. Recognition of this point is crucial to avoid simplified arguments like "which country is happier than others" which neglect differences in important cultural values.

For example, in Japan and Korea, raw scores of happiness and life satisfaction scales are relatively lower than in other industrialized societies (Diener, Diener, \& Diener, 1995). Some researchers argue that the system in Japanese society such as implicit and explicit rules of the workplaces has negative impacts on subjective wellbeing due to "collectivism" and "weakness of individualism." These arguments are partly true, but this "pessimistic and critical view" tends to ignore the cultural meanings of happiness. In addition, cross-cultural "standardized" scales are sometimes invalid when used in some cultures. For instance, Diener et al.'s satisfaction with life scale (Diener, Emmons, Larsen, \& Griffin, 1985) is widely used, but it measures European-American ideas of happiness, which are based upon personal achievement and attainment; indeed, it has been suggested that the scores of that scale reported by Japanese respondents are low since personal achievement is not a central focus for Japanese individuals in regards to wellbeing (e.g., Oishi, 2010).

Cultural psychological research results imply that people in East Asian cultural contexts evaluate their current state of happiness by taking ups and downs in life as a whole into account (Ji, Nisbett, \& Su, 2001). Therefore, if people recognize that their current state is not good enough, but expect it to be improved in the future, their current "unhappiness" is not very negative. In addition, in Japan, where interdependent orientation is salient, being outstandingly happier than others is taken as disharmonious within relationships (Uchida \& Kitayama, 2009). To reflect upon this point, Japanese wellbeing indicators should include questions on "future level of happiness," "ideal level of happiness," and "interdependent happiness" (Hitokoto \& Uchida, 2012). Approaches based on cultural psychological perspectives are necessary, and researchers should focus more on the cultural construal of happiness.

We will review research evidence on the cultural construal of happiness (Table 1 below). Cultural psychological theories have suggested that the Japanese model of the self is based on interdependence (Markus \& Kitayama, 1991; 2010) whereby social relationships are more salient. In contrast, the European-American model of the self is defined in terms of independence, whereby individual freedom and personal rights are more salient. Consistent with these cultural models of the self, sizable cultural differences in happiness and subjective wellbeing emerge (see review; Uchida, Norasakkunkit, \& Kitayama, 2004).

\section{Cross-cultural differences in the meaning of happiness}

\subsection{Cultural background, thinking styles, and the idea of happiness}

Recent cross-cultural evidence suggests there are cultural variations in happiness and subjective wellbeing. It is likely that what constitutes the "good" and "valuable" in life varies substantially across cultures. The cultural construal of happiness is grounded in historically nurtured ideologies and religious ideas. As a consequence, we might expect considerable cross- 
cultural variations in the meaning of happiness and quality of life (Kitayama \& Markus, 2000). In European-American cultural contexts, happiness is defined as a positive emotional state that is typically construed as a state contingent on both personal achievement and maximized positivity of personal attributes (Myers \& Diener, 1995). Negative features of the self, including negative emotional states, are perceived to be a hindrance to happiness. Furthermore, a sense of happiness is based on the incremental model; positive situations are considered to invite more positive outcomes. Individuals within these cultures are motivated to maximize the experience of positive affect. Therefore, individuals are highly motivated to find and affirm the positivity within themselves or their life circumstances. Only recently has the negative side of seeking happiness been shown to invite loneliness (Mauss, Savino, Anderson, Weisbuch, Tamir, \& Laudenslager, 2012) and unhappiness (Mauss, Tamir, Anderson, \& Savino, 2011) within these cultural contexts.

Table 1: Evidence of the cultural construal of happiness

\begin{tabular}{|c|c|c|c|}
\hline Culture & $\begin{array}{c}\text { View of } \\
\text { happiness }\end{array}$ & Meaning of happiness & $\begin{array}{c}\text { Socio-economic factors, } \\
\text { social change }\end{array}$ \\
\hline $\begin{array}{l}\text { European- } \\
\text { American } \\
\text { culture }\end{array}$ & $\begin{array}{l}\text { Positive } \\
\text { Incremental } \\
\text { High arousal }\end{array}$ & $\begin{array}{l}\text { Individual achievement } \\
\text { orientation } \\
\text { - Autonomy } \\
\text { - Agency } \\
\text { - Personal achievement } \\
\text { - Self-esteem }\end{array}$ & $\begin{array}{l}\text { Freedom of choice } \\
\text { High social mobility }\end{array}$ \\
\hline $\begin{array}{l}\text { East Asian } \\
\text { culture }\end{array}$ & $\begin{array}{l}\text { Contains } \\
\text { negative } \\
\text { Dialectical } \\
\text { Low arousal }\end{array}$ & $\begin{array}{cl}\text { Relationship orientation } \\
\text { - } \\
\text { Interdependent } \\
\text { - } \text { happiness } \\
\text { - } \text { Ordinariness } \\
\text { - helationship } \\
\text { - Relational goal } \\
\text { - Social support }\end{array}$ & $\begin{array}{l}\text { Controversial effect of } \\
\text { individualism under } \\
\text { globalization }\end{array}$ \\
\hline
\end{tabular}

There are several reasons why people in European-American cultural contexts seek happiness more than do people in other cultural contexts. Relational mobility is one leading factor (Falk, Heine, Yuki, \& Takemura, 2009; Oishi, Lun, \& Sherman, 2007; Oishi, 2010; Yuki et al., 2007). Relational mobility assumes that the person is within a socio-economic situation, such as a relational market, and that personal choices are an inalienable right. For example, Yuki et al. (2007) defined relational mobility as the amount of "choice" afforded in interpersonal relationships. They suggested that people with high relational mobility (i.e., people in the United States) have a fair amount of opportunity to establish new relationships; therefore, they do not tend to insist on a given relationship but rather seek more favorable relational opportunities. Based on this mechanism, people in a society with high social mobility are expected to discover their positive internal resources, such as high self-esteem, to obtain better opportunities.

In addition to the socio-economic environment, religious and ethical ideas are also related to views of happiness. For example, there are close ties between the European-American view 
of happiness and the Protestant worldview. Max Weber (1920) pointed out that capitalist societies and individualism are associated with the Protestant worldview. According to this worldview, individuals are predestined to be "selected" or "doomed" (Weber, 1920). The belief in predestination generates a strong desire to affirm the worthiness of the self through hard work and to obtain positive outcomes, and, thus, as being "selected" by God. Affirmation of personal worthiness, such as feeling happiness, might serve as an effective buffer against anxiety (negative prospect of the self); thus, there is a high motivation to seek happiness.

In contrast, in East Asian cultures, balance among social relationships is important. This might be related to the socioeconomic environment. For instance, the society that is derived from an agricultural economy in Japan or China requires collective cooperation in order to maintain important "public goods", such as the water supply system. In addition, agricultural communities have low social mobility in general. Yuki et al. (2007) suggest that the cost of isolation from a given society is greater for East Asian, low-social-mobility contexts as compared to European-American, high-social-mobility contexts. Thus, the motivation for maintaining group and relationship harmony is more salient in East Asian societies than is the motivation for maximizing individual goals. Furthermore, the Asian cultural construal of happiness is related to certain strands of ideas revealed in Confucianism, Taoism, and Buddhism. All these ideologies and worldviews emphasize a holistic or dialectical world order where everything is assumed to be connected with everything else (Kitayama \& Markus, 1999; Peng \& Nisbett, 1999). Positive and negative aspects can coexist, and the total amount of positivity and negativity in one's life can be seen as equal. What is good or bad personally is often a cause for opposite social consequences. Therefore, Japanese individuals evaluate their current situation from a more transcendental point of view.

Based on the different background between Asian cultures and European-American cultures, several studies have suggested that, within European-American cultures, positivity and negativity are often seen as contradictory while they are seen as complementary among East Asian cultures. For example, Bagozzi, Wong, and Yi (1999) measured the reported intensity of pleasant and unpleasant emotions and observed that these two types of emotion were negatively correlated in the United States, whereas they were positively correlated in China and Korea (see also Kitayama, Markus, \& Kurokawa, 2000). Similar findings have been revealed in recent studies examining cross-cultural differences in the experience of emotion. Furthermore, Miyamoto, Uchida, and Ellsworth (2010) found that Japanese individuals experience mixed (positive and negative) emotions more often when in a happy situation than do Americans. Additionally, this dialectic emotional experience positively predicts physical health among Japanese (Miyamoto \& Ryff, 2011).

The notion of dialecticism vs. bipolar emotional experiences might be related to cognitive aspects, namely changes in prediction and motivation. With regard to cognitive aspects, Ji et al. (2001) presented Chinese and American participants with graphs representing either a linear or nonlinear trend, and asked participants to indicate which graph might best represent the change in their happiness over the lifespan. Chinese respondents were more likely to choose a nonlinear graph while Americans were more likely to choose a linear graph. In addition, participants were shown several points of a trend within a graph (e.g., economic performance in January and February) and then asked to predict what would happen next. The results showed that Chinese participants predicted more deviations from the initially presented trend compared to American participants. The Chinese exhibited a style of cognition referred to as "dialectic thinking," which has been found to be more prevalent among East Asians relative to Americans over several studies. 
Few studies have investigated the cultural construal of happiness from a basic analysis of the meaning of "happiness" but Uchida and Kitayama (2009) used a systematic approach to explore individuals' knowledge of happiness and unhappiness in the United States and Japan. Their results suggested that Americans believe happiness is a relatively enduring positive state that should be pursued personally, whereas Japanese are likely to believe that happiness is a relatively positive, transitory interpersonal moment and, yet, that it is also fraught with numerous negative consequences. In the first part of Uchida and Kitayama's study, both American and Japanese participants were asked to describe up to five features, effects, or consequences of happiness. After describing these features, participants were asked to rate each feature in terms of general desirability. Results showed that over $98 \%$ of American descriptions were reported as positive, whereas only $67 \%$ of Japanese descriptions were reported as positive. In the second part of their study, a large number of features collected in the first part of the study were printed on separate index cards. A stack of cards was then presented to a new group of participants from each culture (i.e., meanings of happiness obtained in the United States were shown to American participants only). These participants were asked to sort the cards according to perceived similarities of the descriptions. On the basis of this data, the likelihood of each pair of descriptions being classified into the same category was calculated. This likelihood (an index of perceived similarities among the features of happiness) was used to compute a multidimensional scaling solution. In both cultures, three types of descriptions were commonly observed: general hedonic states (e.g., joy, excitement, and positive attitude), personal achievement (e.g., getting a good grade, getting a job) and interpersonal harmony (e.g., getting along with others, having a party for a friend). In addition to these cultural similarities, two other clusters of negative features of happiness were obtained from the Japanese group. One such negative feature of happiness was transcendental reappraisal, which included avoidance (e.g., letting people avoid reality), nihilism (e.g., not lasting long), and transcendental realization (e.g., difficult to identify). The other cluster was social disruption, which included negative social consequences (e.g., envy and jealousy from others) and inattention (e.g., failing to pay enough attention to one's surroundings). These negative clusters were largely absent within the American sample.

Uchida (2011) also observed that people within Japanese cultural contexts are more likely to think of negative features as valid aspects of happiness when judging features of happiness obtained from Uchida and Kitayama (2009). Furthermore, they showed that this Japanese holistic view is associated with a holistic worldview within certain cognitive states (Choi, Koo, \& Choi, 2007) regardless of their current subjective state of happiness.

\subsection{Arousal and happiness: cultural valuation}

Tsai and colleagues have proposed the "Affect Valuation Theory", which suggests that each cultural context has an "ideal affect" (how people want to feel) and "actual affect" (how they actually feel). Tsai, Knutson, and Fung (2006) suggest that culture influences ideal affect more than it influences actual affect. For instance, Americans value high-arousal positive affect (e.g., excitement) more than do Hong Kong Chinese individuals, who place greater value on lowarousal positive affect (e.g., calmness). Ideal affect is learned through the family and education and transmitted from generation to generation. An analysis of bestseller picture books for children in the United States and in Taiwan shows best-selling U.S. picture books have protagonists with larger smiles than are present in Taiwanese bestsellers, and the actions those characters are depicted as taking are more reflective of "high-arousal" emotions than are the 
actions characters in the Taiwanese picture books are depicted as taking. Picture books in Taiwan and Japan show calmer images with the depiction of "low-arousal" emotions (Tsai, Louie, Chen, \& Uchida, 2007; see also Oyama et al., 2008). Tsai and colleagues examined the way in which children were differentially affected by these varying emotional displays within picture books. After exposure to a high-arousal picture book, American children were more likely to recognize "large smile" facial expressions as "happy" than after exposure to a lowarousal picture book (Tsai, Louie et al., 2007, Study 2).

\section{Predictors of happiness: personal goal attainment vs. relationship orientation}

If cultural construal of happiness differs across cultures, the predictor of happiness should also differ. In this section, we focus on difference between predictors of happiness in cultures oriented to individual achievement and those oriented to relationships.

Individuals within independent cultural contexts (Markus \& Kitayama, 1991) are motivated to maximize the experience of positive affect and are motivated to seek happiness by autonomous agency. In contrast, within East Asian cultural contexts, happiness tends to be defined in terms of interpersonal connectedness or balance between the self and others (see Uchida, Norasakkunkit, \& Kitayama, 2004 for a review). The examination of the axis between "personal achievement orientation" and "relationship orientation" is valid and several crosscultural studies have been conducted using this approach.

Ryff and colleagues proposed the concept of eudaimonic wellbeing, measured with six scales assessing psychological wellbeing (Ryff, 1989; Ryff \& Keyes, 1995). Eudaimonic wellbeing includes autonomy, environmental mastery, personal growth, self-acceptance, positive relations with others, and purpose in life. These aspects, except for "positive relations with others," are based on the independence and autonomy of the self. In addition, within European-American cultural contexts, the factor that tends to be the most correlated with happiness is self-esteem (Campbell, 1981; Diener \& Diener, 1995; Diener et al., 1985). Likewise, accomplishing personal goals predicts positive emotional states. For example, Taylor and Brown (1988) argued that the perception of one's positivity and effectiveness, even when it is illusory, can contribute to mental health. Other similar factors such as achievement of independent goals (Emmons, 1986, 1991; Oishi \& Diener, 2001) and positive but non-relational emotional experiences (Kitayama, Mesquita, \& Karasawa, 2006) are strong predictors of happiness, subjective wellbeing, and life satisfaction within European-American cultural contexts.

In contrast, interpersonal factors, such as adapting to social norms and fulfilling relational obligations, tend to increase life satisfaction among people within East Asian cultural contexts. Other factors, such as attainment of interpersonal goals over personal goals (Oishi \& Diener, 2001), positive relational emotional experiences (Kitayama et al., 2006), receiving emotional support (Uchida, Kitayama, Mesquita, Reyes, \& Morling, 2008), fulfilling relational norms (Suh, Diener, Oishi, \& Triandis, 1998), and relational harmony (Kwan, Bond, \& Singelis, 1997), are highly predictive of happiness and wellbeing among Asians. In addition, in East Asian contexts, the significance of self-esteem is questionable. Diener and Diener (1995) investigated 31 countries and found that self-esteem is more strongly correlated with subjective wellbeing in individualistic (e.g., European-American) cultures than in collectivistic (e.g., East Asian) cultures.

Social relationships are also important within European-American cultures. For example, perceived availability of support provides a variety of beneficial effects on health and wellbeing (e.g., Cohen \& Wills, 1985; Uchino, Cacioppo, \& Kiecolt-Glaser, 1996). Studies of 
emotional support using European-American samples describe effects of support as they relate to self-esteem. In line with a strong emphasis on self-esteem, individuals within EuropeanAmerican cultures see social relationships as important because they affirm a sense of positive self-worth or self-esteem (Leary, Tambor, Terdal, \& Downs, 1995). On the other hand, if support fails to maintain self-esteem (i.e., feeling too dependent on others), support's effect on happiness tends to deteriorate. Indeed, some studies in the United States show that perceived emotional support sometimes fails to provide positive effects on wellbeing and health (Bolger \& Amarel, 2007; Bolger, Foster, Vinokur, \& Ng, 1996; Bolger, Zuckerman, \& Kessler 2000; Fisher, Nadler, \& Whitcher-Alagna, 1982; Seidman, Shrout, \& Bolger, 2006). Fisher et al. (1982) reviewed a series of studies and found that recipients of support often experience negative consequences, such as feelings of failure and dependency. Similarly, invisible support might work better since it has not been shown to be harmful to self-esteem (Bolger \& Amarel, 2007). In sum, it is likely that within European-American cultural contexts, emotional support, such as encouragement, compassion, and sympathy often provides ambivalent meanings; this might signify both worthiness of the self and weakness of the self. As a consequence, emotional support might contribute to happiness only to the extent that support does not threaten selfesteem.

Indeed, Uchida and colleagues (2008) found that in two different Asian cultures (Japan and the Philippines) both self-esteem and perceived emotional support were equally predictive of happiness (see Table 2). However, in the American sample, once self-esteem was controlled, the effect of emotional support on happiness vanished, and self-esteem was the only remaining predictor of happiness in the U.S. sample. With respect to patient quality of life, Ikeda and colleagues (2011) suggested that perceived emotional support is quite effective for Japanese diabetic patients' higher compliance with treatment protocols for coping with their disease. However, the effect of emotional support was found to be weaker among American diabetic patients, who are focusing on their competence to cope with the disease.

Table 2: Regression coefficients of Emotional Support to Happiness (Uchida, et al., 2008).

\begin{tabular}{lccc}
\hline & Japan $(N=256)$ & Philippines $(N=243)$ & U.S. $(N=160)$ \\
\hline Support $\rightarrow$ Happiness & $0.42^{* * * *}$ & $0.39^{* * *}$ & $0.25^{* *}$ \\
$\begin{array}{l}\text { Support } \rightarrow \text { Happiness } \\
\text { self-esteem controlled) }\end{array}$ & $0.35^{* * *}$ & $0.30^{* * * *}$ & 0.08 \\
\hline
\end{tabular}

${ }^{* *} p<.01,{ }^{* * *} p<.001$

\section{Happiness and globalization: the effect of individualism}

It has been suggested that increasing wealth might be influential to individual wellbeing insofar as it allows individuals to have greater autonomy and freedom in their daily life. Thus, wealth likely affects happiness only through its effect on individual autonomy and freedom of choice (Fisher \& Boer, 2011; Inglehart, Foa, Peterson, \& Welzel, 2008).

This point, suggesting a relationship between individualism and wellbeing, places importance on individual freedom. As some studies have suggested, the effect of individual freedom on wellbeing might be seen across cultures. From a meta-theoretical standpoint, 
however, this framework has been influenced by the "independence" model of the cultural construal of happiness shared in European-American contexts. For example, if we used a measure such as interdependent happiness (Hitokoto \& Uchida, 2012), based on relationshiporiented happiness or dialectical happiness, the correlation between individualism and happiness would be questionable.

\subsection{Wellbeing and Deviation from the Cultural Mainstream}

Most cultural psychological research has examined mainstream behaviors or emotions within cultures. However, culture itself is not a static "object"; rather, it is a dynamic system that inherently contains individual variance within a culture. Thus, some people display behaviors that are not consistent with mainstream cultural values.

Previous research has suggested that seeking goals that are consistent with mainstream cultural values increases wellbeing (e.g., Oishi \& Diener, 2001; Uchida et al., 2008). For example, seeking relationship harmony within East Asian cultures and seeking individual achievement within European-American cultures increases happiness, respectively.

Will seeking goals that are not consistent with mainstream cultural values (i.e., seeking individual achievement in East Asian cultural contexts) decrease wellbeing? Ogihara and Uchida (2010) examined this issue in order to see the periphery of culture, which is not cultural mainstream. In this study, a questionnaire study with college students in Japan and the United States was conducted. Students in both countries were asked to evaluate the extent to which they focused on achievement orientation and relationship orientation, using the Contingencies of Self-Worth Scale (Crocker, Luhtanen, Cooper, \& Bouvrette, 2003; Uchida, 2008). Results indicated that, for Japanese participants, achievement orientation significantly decreased wellbeing, whereas relationship orientation did not predict wellbeing. On the other hand, relationship orientation significantly decreased wellbeing in the U.S. sample, whereas achievement orientation did not predict wellbeing. These results showed that deviation from the cultural mainstream decreased wellbeing (Ogihara \& Uchida, 2010).

Individualism has spread throughout Japan due to globalization (Toivonen, Norasakkunkit, \& Uchida, 2011), both at the personal and at the macro levels. At the personal level, for instance, average family size has decreased, the divorce rate has increased, and the importance of independence during child socialization has increased. This indicates that Japanese individuals have become more individualistic in some respects (Hamamura, 2012). In addition, at the macro level, for example, the system of individualism has been employed in many companies (i.e., individual achievement-based evaluation; Joe, 2004; Takahashi, 2010). As a consequence, people in Japan are faced with achievement-oriented situations more often than before. Such cultural shifts might decrease happiness in Japan. To examine this hypothesis, Ogihara and Uchida (2012) conducted an experimental study in which Japanese undergraduate students were randomly assigned to one of three conditions (achievement-oriented condition, relationship-oriented condition, or control condition). They were asked to imagine and describe a situation in which they were in a workplace where their worth would be determined by their personal achievement (achievement-oriented condition) or the quality of their relationships with others (relationship-orientated condition). Participants in the control condition were asked to imagine and describe a workplace setting without any specific instructions. Next, participants reported their wellbeing under that imagined situation. Results indicated that participants in the achievement-oriented condition reported lower wellbeing than did participants in the control condition. There was no difference in wellbeing between the relationship and control conditions. 
Why did achievement orientation decrease subjective wellbeing? We recently observed that interpersonal relationships might deteriorate when Japanese seek individualism. For example, in the survey study (Ogihara \& Uchida, 2010), the number of close friends mediated the negative effect of achievement orientation on subjective wellbeing, which means that those who were highly achievement-oriented had fewer close friends and thus they reduced happiness. Similarly in the experimental study (Ogihara \& Uchida, 2012), the amount of social support expected to be obtained mediated the negative effect of achievement orientation on subjective wellbeing. In sum, achievement orientation (both at the individual and institutional level) makes it difficult for Japanese individuals to build and maintain good relationships with others; this can lead to decreased wellbeing. Interestingly, we did not find this negative relationship between individualism and happiness in a sample of U.S. participants.

These findings are consistent with an argument presented by Kitayama (2010, 2012). He suggests that individualism in Japan might be qualitatively different from individualism in the United States, that is, individualism in Japan is more likely to be interpreted as "doing something alone by himself/herself," thus individualism in Japan has connotations of "egoism" or "social isolation." Kitayama (2012) also introduced the description by a famous historical author, Souseki Natsume (1867-1916), who pointed out that individualism was interpreted as egoism in 1914, a hundred years ago. This interpretation still exists in the current Japanese situation. Such "egoistic independence" leads to social isolation (Kitayama, 2012).

In a society where independence of the self is salient, such as European-American cultures, the system of individualism prevails and works well within each institution or organization. Within that culture, competitiveness and relational mobility are quite high, and people pay attention to individual ability and respect personal strategies and uniqueness. Therefore, individuals are independent from each other but still actively build and maintain interpersonal relationships. In contrast, in a society where the interdependent self is salient, such as Japanese culture, the system of individualism is interpreted as a situation in which one has become isolated from interpersonal relationships. Japanese individuals tend to think that they would have to cut off relationships with others in order to be independent and to achieve individualism. A number of Japanese individuals might have attempted to do this under the pressure of globalization. However, happiness in Japan is still strongly related to interpersonal relationships, given that implicit and basic cultural norms are still interdependent. The speed of system change within a society and the psychological change within an individual are inconsistent. Even though globalization has affected Japanese society, traditional Japanese cultural values of interdependence still exist. The discrepancy between explicit norms (global standards) and implicit norms (traditional standards) might lead to decreases in happiness among Japanese individuals (Kitayama, 2010). So far we have argued the case of Japan as an example of a country that is under pressure from globalization, but similar examples might be found within other Asian cultural contexts that are also experiencing the shifting of cultural norms towards European-American ideas of happiness.

\section{Changing happiness after national disasters}

Japan experienced the Great East Japan Earthquake on March 11, 2011. It was an exceptionally severe disaster, certainly the worst in recent memory. Both the earthquake itself and the tsunami brought disaster on a massive scale throughout the region. More than 15,800 people died, and around 3,700 people are still missing as of May 2012. Uchida, Takahashi, and Kawahara (2011) examined how the Great East Japan earthquake has affected the happiness of young people in Japan outside of the afflicted area. A large longitudinal survey $(N=10,744)$ 
was conducted before the earthquake (December 2010) and another after it (March 2011). People who were Thinking about the Earthquake while completing the second survey (TE group: $40 \%$ of the sample) were happier after the earthquake than before, showing that reflecting on the earthquake had prompted them to reevaluate their definition of happiness. They also experienced temporary negative emotional reactions more frequently after the earthquake than before. In contrast, those who were Not Thinking about the Earthquake while answering the survey (NTE group: approximately $48 \%$ of the sample) did not record a change in their level of happiness and actually felt less happiness, even before the earthquake, than did the TE group.

It seems that the TE group were more likely to change their definition of happiness after the earthquake, and this reevaluation of their values might have prompted them to become more satisfied with their current life conditions. Those who had felt less general happiness before the earthquake were less likely to reflect upon the earthquake and tended not to change their definitions of happiness.

The two different reactions (TE vs. NTE) among Japanese young adults might reflect recent conflicts between traditional cultural values and new ideas of individualism. The TE group might be more likely to have traditional values whereas the NTE group might be more likely to have new "individualistic" ideas. The current Japanese model of happiness might also include these two dichotomous patterns.

\section{Future direction for research on happiness from a cultural psychological point of view}

We have reviewed several studies on happiness based on the cultural construal of happiness. At an abstract level, conceptions of happiness can be seen as universal in terms of satisfaction with one's accomplishments and relationships; however, the degree to which each of these factors is emphasized and predicts happiness can vary substantially from culture to culture. Furthermore, connotations of happiness also differ, such as incremental views of happiness observed in European-American cultures and dialectic views of happiness observed among East Asian cultures.

Such cultural differences are found not only at the individual psychological level but also at the macro level, such as within societal systems, institutions, and among scientific metatheories. Based on these cultural differences, situational/environmental factors (such as globalization and national disaster) can also affect views of happiness differently within society. We have to illustrate not only cross-cultural differences but also illustrate cultural/societal changes over time within nations or communities.

Further research on happiness across cultures will have an impact on people's societal wellbeing. From a cultural psychological point of view, we have to point out several "cautions" for cross-cultural comparisons. First, regarding response biases (i.e., Asians prefer to use a middle point but Americans prefer to use an extreme point on a Likert scale; Chen, Lee, \& Stevenson, 1995) and the reference group effect (i.e., people judge themselves based on surrounding others; individual judgment in each nation varies with their "reference point"; Heine, Lehman, Peng, \& Greenholtz, 2002), we have to be careful with simple mean score comparisons (e.g., Heine et al., 2002). Second, as set-point theory suggested (see Diener, Lucas, \& Scollon, 2006), each individual has a different set-point of wellbeing regarding his or her individual life experiences. Inglehart and Klingemann (2000) have also suggested that there have been large stable differences of the life satisfaction among various societies for at least 20 years, for each culture has a normal set-point (baseline) of wellbeing based on historical experience. Again, these set-point differences make it harder to interpret mean cultural comparisons. Third, and more importantly, we have to consider that "optimal happiness" 
varies substantially across cultures. For example, life satisfaction scales, or ladder scales, which are frequently used in cross-cultural studies, are based on the concept of wellbeing as being based on individual achievement. Thus, there is an inherent bias that is embedded in these measures. Therefore, individuals within Asian cultures are sometimes judged to be "less healthy" and "more emotionally distressed" than American or European samples (e.g., Norasakkunkit \& Kalick, 2002).

Instead of simple mean score comparisons and using "happiness rankings," investigating the meaning of happiness within each cultural context would be more productive. In addition, using several indices, including measures that reflect cultural construals of happiness in a given culture, would be helpful. We believe that cultural psychological perspectives will contribute to our understanding of wellbeing across a variety of cultural contexts.

\section{Authors}

Yukiko Uchida

Kyoto University

yukikou@educ.kyoto-u.ac.jp

Yuji Ogihara

Kyoto University

\section{Publishing Timeline}

Received 30 May 2012

Accepted 28 August 2012

Published 13 December 2012

\section{References}

Adams, G., \& Markus, H. R. (2004). Culture as patterns: An alternative approach to the problem of reification. Culture and Psychology, 7, 283-296. http://dx.doi.org/10.1177/1354067X0173002

Bagozzi, R. P., Wong, N., \& Yi, Y. (1999). The role of culture and gender in the relationship between positive and negative affect. Cognition and Emotion, 13, 641-672. http://dx.doi.org/10.1080/026999399379023

Bolger, N., \& Amarel, D. (2007). Effects of social support visibility on adjustment to stress: Experimental evidence. Journal of Personality and Social Psychology, 92, 458-475. http://dx.doi.org/10.1037/00223514.92.3.458

Bolger, N., Foster, M., Vinokur, A. D., \& Ng, R. (1996). Close relationship and adjustments to a life crisis: The case of breast cancer. Journal of Personality and Social Psychology, 70, 283-294.

Bolger, N., Zuckerman, A., \& Kessler, R. C. (2000). Invisible support and adjustment to stress. Journal of Personality and Social Psychology, 79, 953-961.

Bruner, J. S. (1990). Acts of meaning. Cambridge, MA: Harvard University Press.

Campbell, A. (1981). The sense of well-being in America. New York: McGraw-Hill.

Center for Bhutan Studies. (2012). Gross national happiness. http://www.grossnationalhappiness.com/

Chen, C., Lee, S-Y., \& Stevenson, H. W. (1995). Response style and cross-cultural comparisons of rating scales among East Asian and North American students. Psychological Science, 6, 170-175.

http://dx.doi.org/10.1111/j.1467-9280.1995.tb00327.x

Choi, I., Koo, M., \& Choi, J. A. (2007). Individual differences in analytic versus holistic thinking. Personality and Social Psychology Bulletin, 33, 691-705. http://dx.doi.org/10.1177/0146167206298568

Cohen, S., \& Wills, T. A. (1985). Stress, social support, and the buffering hypothesis. Psychological Bulletin, 


\section{8, 310-357. http://dx.doi.org/10.1037/0033-2909.98.2.310}

Crocker, J., Luhtanen, R. K., Cooper, M. L., \& Bouvrette, A. (2003). Contingencies of self-worth in college students: Theory and measurement. Journal of Personality and Social Psychology, 85, 894-908. http://dx.doi.org/10.1037/0022-3514.85.5.894

Diener, E., \& Diener, M. (1995). Cross-cultural correlates of life satisfaction and self-esteem. Journal of Personality and Social Psychology, 68, 653-663. http://dx.doi.org/10.1037/0022-3514.68.4.653

Diener, E., Diener, M., \& Diener, C. (1995). Factors predicting the subjective well-being of nations. Journal of Personality and Social Psychology, 69, 851-864. http://dx.doi.org/10.1037/0022-3514.69.5.851

Diener, E., Emmons, R. A., Larsen, R. J., \& Griffin, S. (1985). The satisfaction with life scale. Journal of Personality Assessment, 49, 71-75. http://dx.doi.org/10.1207/s15327752jpa4901_13

Diener, E., Lucas, R. E., \& Scollon, C. N. (2006). Beyond the hedonic treadmill: Revising the adaptation theory of well-being. American Psychologist, 61, 305-314. http://dx.doi.org/10.1037/0003-066X.61.4.305

Diener, E. \& Suh, E. M. (2000). Cultural and subjective well-being. The MIT Press, Cambridge, MA.

Easterlin, R. A. (1973). Does money buy happiness? The Public Interest, 30, 3-10.

Emmons, R. A. (1986). Personal strivings: An approach to personality and subjective well-being. Journal of Personality and Social Psychology, 51, 1058-1068. http://dx.doi.org/10.1037/0022-3514.51.5.1058

Emmons, R.A. (1991). Personal strivings, daily life events, and psychological and physical well-being. Journal of Personality, 59, 453-472. http://dx.doi.org/10.1111/j.1467-6494.1991.tb00256.x

Falk, C. F., Heine, S. J., Yuki, M., \& Takemura, K. (2009). Why do Westerners self-enhance more than East Asians? European Journal of Personality, 23, 183-203. http://dx.doi.org/10.1002/per.715

Fisher, R., \& Boer, D. (2011). What is more important for national well-being: Money or autonomy? Journal of Personality and Social Psychology, 101, 164-184. http://dx.doi.org/10.1037/a0023663

Fisher, J. D., Nadler, A., \& Whitcher-Alagna, S. (1982). Recipient reactions to aid. Psychological Bulletin, 91, 27-54. http://dx.doi.org/10.1037/0033-2909.91.1.27

Hamamura, T. (2012). Are cultures becoming individualistic? A cross-temporal comparison of individualism-collectivism in the U.S. and Japan. Personality and Social Psychological Review, 16, 3-24. http://dx.doi.org/10.1177/1088868311411587

Heine, S. J., Lehman, D. R., Peng, K., \& Greenholtz, J. (2002). What's wrong with cross-cultural comparisons of subjective Likert scales: The reference-group problem. Journal of Personality and Social Psychology, 82, 903-918. http://dx.doi.org/10.1037/0022-3514.82.6.903

Hitokoto, H., \& Uchida, Y. (2012). Interdependent happiness: Cross-cultural and regional comparisons. Unpublished Manuscript, Kwansai Gakuin University.

Ikeda, K., Fujimoto, S., Uchida, Y., Takahara, S., Carroll, A., Morling, B., \& Inagaki, N. (2011, June). Impact of cultural views of self and perceived emotional support on diabetes self-care outcomes. The 71st Scientific Sessions of American Diabetes Association. June 24-28, San Diego Convention Center, San Diego, CA.

Inglehart, R. F., Foa, R., Peterson C., \& Welzel, C. (2008). Development, freedom, and rising happiness: A global perspective (1981-2007). Perspectives on Psychological Science, 3, 264-285. http://dx.doi.org/10.1111/j.1745-6924.2008.00078.x

Inglehart, R., \& Klingemann, H-D. (2000). Genes, culture, democracy, and happiness. In E. Diener, \& E. M. Suh (Eds.), Cultural and subjective well-being (pp. 165-183). Cambridge, MA: The MIT Press.

Ji, L., Nisbett, R. E., \& Su, Y. (2001). Culture, change, and prediction. Psychological Science, 12, 450-456. http://dx.doi.org/10.1111/1467-9280.00384

Joe, S. (2004). The inside of FUJITSU. Kobunsha, Tokyo, Japan.

Kitayama, S. (2010). Frontiers in social and behavioral science: For a new pioneering. In H. Ishiguro \& T. Kameda (Eds.), Culture and practice (pp. 199-244). Shin'yosha, Tokyo, Japan. 
Kitayama, S. (2012). Individualism and happiness: A comment on Uchida \& Ogihara (2012). Japanese Psychological Review, 55, 43-46.

Kitayama, S., \& Markus, H. R. (1999). Yin and yang of the Japanese self: The cultural psychology of personality coherence. In D. Cervone \& Y. Shoda (Eds.), The coherence of personality: Social cognitive bases of personality consistency, variability, and organization (pp. 242-302). New York: Guilford Press.

Kitayama, S., \& Markus, H. R. (2000). The pursuit of happiness and the realization of sympathy: Cultural patterns of self, social relations, and well-being. In E. Diener, \& E. M. Suh (Eds.), Cultural and subjective well-being (pp. 113-161). Cambridge, MA: The MIT Press.

Kitayama, S., Markus, H. R., \& Kurokawa, M. (2000). Culture, emotion, and well-being: Good feelings in Japan and the United States. Cognition and Emotion, 14, 93-124.

http://dx.doi.org/10.1080/026999300379003

Kitayama, S., Duffy, S., \& Uchida, Y. (2007). Self as cultural mode of being. In S. Kitayama, D. Cohen (Eds.), Handbook of cultural psychology, pp. 136-174. New York: Guilford Press.

Kitayama, S., Park, H., Sevincer, A. T., Karasawa, M., \& Uskul, A. K. (2009). A cultural task analysis of implicit independence: Comparing North America, Western Europe, and East Asia. Journal of Personality and Social Psychology, 97, 236-255. http://dx.doi.org/10.1037/a0015999

Kitayama, S., Mesquita, B., \& Karasawa, M. (2006). Cultural affordance and emotional experience: Socially engaging and disengaging emotions in Japan and the United States. Journal of Personality and Social Psychology, 91, 890-903. http://dx.doi.org/10.1037/0022-3514.91.5.890

Kwan, V. S. Y., Bond, M. H., \& Singelis, T. M. (1997). Pancultural explanations for life satisfaction: Adding relationship harmony to self-esteem. Journal of Personality and Social Psychology, 73, 10381051. http://dx.doi.org/10.1037/0022-3514.73.5.1038

Leary, M. R., Tambor, E. S., Terdal, S. K., \& Downs, D. L. (1995). Self-esteem as an interpersonal monitor: The sociometer hypothesis. Journal of Personality and Social Psychology, 68, 518-530. http://dx.doi.org/10.1037/0022-3514.68.3.518

Markus, H. R., \& Kitayama, S. (1991). Culture and the self: Implications for cognition, emotion, and motivation. Psychological Review, 98, 224-253. http://dx.doi.org/10.1037/0033-295X.98.2.224

Markus, H. R., \& Kitayama, S. (2010). Cultures and selves: A cycle of mutual constitution. Perspectives on Psychological Science, 5, 420-430. http://dx.doi.org/10.1177/1745691610375557

Mauss, I. B., Savino, N.S., Anderson, C. L., Weisbuch, M., Tamir, M., \& Laudenslager, M. L. (2012). The pursuit of happiness can be lonely. Emotion, 12, 908-912.

Mauss, I. B., Tamir, M., Anderson, C. L., \& Savino, N. S. (2011). Can seeking happiness make people unhappy? Paradoxical effects of valuing happiness. Emotion, 11, 807-815. http://dx.doi.org/10.1037/a0022010

Miyamoto, Y. \& Ryff, C. D. (2011). Cultural differences in the dialectical and non-dialectical emotion styles and their implications for health. Cognition and Emotion, 25, 22-39. http://dx.doi.org/10.1080/02699931003612114

Miyamoto, Y., Uchida, Y., \& Ellsworth, P. C. (2010). Culture and mixed emotions: Co-occurrence of positive and negative emotions in Japan and the United States. Emotion, 10, 404-415. http://dx.doi.org/10.1037/a0018430

Myers, D. G., \& Diener, E. (1995). Who is happy? Psychological Science, 6, 10-19. http://dx.doi.org/10.1111/j.1467-9280.1995.tb00298.x

Norasakkunkit, V., \& Kalick, S. M. (2002). Culture, ethnicity, and emotional distress measures: The role of self-construal and self-enhancement. Journal of Cross-Cultural Psychology, 33, 56-70. http://dx.doi.org/10.1177/0022022102033001004 
Ogihara, Y., \& Uchida, Y. (2010, September). Subjective well-being of adolescents in Japan and the U.S.: Contingency of self-worth and interpersonal relationships. Poster presented at the 51st Annual Meeting of the Japanese Society of Social Psychology, Hiroshima, Japan.

Ogihara, Y., \& Uchida., Y. (2012, January). Does personal achievement orientation have negative effect for Japanese? Cultural analysis of personal achievement versus relationships orientation. Poster presented at the 13th Annual Meeting of Society for Personality and Social Psychology, San Diego, CA.

Oishi, S. (2010). The psychology of residential mobility: Implications for the self, social relationships, and well-being. Perspectives on Psychological Science, 5, 5-21. http://dx.doi.org/10.1177/1745691609356781

Oishi, S. (2012). The psychological weal th of nations: Do happy people make a happy society (Contemporary social issues). Wiley-Blackwell, UK.

Oishi, S., \& Diener, E. (2001). Goals, culture, and subjective well-being. Personality and Social Psychology Bulletin, 27, 1674-1682. http://dx.doi.org/10.1177/01461672012712010

Oishi, S., Lun, J., \& Sherman, G. D. (2007). Residential mobility, self-concept, and positive affect in social interactions. Journal of Personality and Social Psychology, 93, 131-141. http://dx.doi.org/10.1037/00223514.93.1.131

Oyama, T., Agostini, T., Kamada, A., Marković, S., Osaka, E., Sakurai, S., Sarmány-schuller, I., \& Sarris, V. (2008). Similarities in form symbolism among various languages and geographical regions. Psychologia, 51, 170-184. http://dx.doi.org/10.2117/psysoc.2008.170

Peng, K., \& Nisbett, R. E. (1999). Culture, dialecticism, and reasoning about contradiction. American Psychologist, 54, 741-754. http://dx.doi.org/10.1037/0003-066X.54.9.741

Ryff, C. D. (1989). Happiness is everything, or is it? Explorations on the meaning of psychological wellbeing. Journal of Personality and Social Psychology, 57, 1069-1081. http://dx.doi.org/10.1037/00223514.57.6.1069

Ryff, C. D., \& Keyes, C. L. M. (1995). The structure of psychological well-being revisited. Journal of Personality and Social Psychology, 69, 719-727. http://dx.doi.org/10.1037/0022-3514.69.4.719

Seidman, G., Shrout, P. E., \& Bolger, N. (2006). Why is enacted social support associated with increased distress? Using simulation to test two possible sources of spuriousness. Personality and Social Psychology Bulletin, 32, 52-65. http://dx.doi.org/10.1177/0146167205279582

Shweder, R. A. (1991). Cultural psychology: What is it? In R. A. Shweder (Ed.), Thinking through cultures: Expeditions in cultural psychology (pp. 73-110). Cambridge, MA: Harvard University Press.

Suh, E. M., Diener, E., Oishi, S., \& Triandis, H. C. (1998). The shifting basis of life satisfaction judgments across cultures: Emotions versus norms. Journal of Personality and Social Psychology, 74, 482-493. http://dx.doi.org/10.1037/0022-3514.74.2.482

Takahashi, N. (2010). Kyomou no seikashugi: Nihongata nenko seido fukkatsu no susume (Fallacy of Pay-perperformance system in Japan: Recommendation of seniority criterion system). Chikuma-Syobo, Tokyo, Japan.

Taylor, S. E., \& Brown, J. D. (1988). Illusion and well-being: A social psychological perspective on mental health. Psychological Bulletin, 103, 193-210. http://dx.doi.org/10.1037/0033-2909.103.2.193

Toivonen, T., Norasakkunkit, V., and Uchida, Y. (2011). Unable to conform, unwilling to rebel? Youth, culture, and motivation in globalizing Japan. Frontiers in Cultural Psychology, 2, 207. http://dx.doi.org/10.3389/fpsyg.2011.00207

Tsai, J. L., Knutson, B., \& Fung, H. H. (2006). Cultural variation in affect valuation. Journal of Personality and Social Psychology, 90, 288-307. http://dx.doi.org/10.1037/0022-3514.90.2.288

Tsai, J. L., Louie, J., Chen, E. E., \& Uchida, Y. (2007). Learning what feelings to desire: Socialization of ideal affect through children's storybooks. Personality and Social Psychology Bulletin, 33, 17-30. http://dx.doi.org/10.1177/0146167206292749 
Uchida, Y. (2008). Contingencies of self-worth in Japanese culture: Validation of Japanese contingencies of self-worth scale. Japanese Journal of Psychology, 79, 250-256. http://dx.doi.org/10.4992/jjpsy.79.250

Uchida, Y. (2011). A holistic view of happiness: Belief in the negative side of happiness is more prevalent in Japan than in the United States. Psychologia, 53, 236-245. http://dx.doi.org/10.2117/psysoc.2010.236

Uchida, Y., \& Kitayama, S. (2009). Happiness and unhappiness in east and west: Themes and variations. Emotion, 9, 441-456. http://dx.doi.org/10.1037/a0015634

Uchida, Y., Kitayama, S., Mesquita, B., Reyes, J. A. S., \& Morling, B. (2008). Is perceived emotional support beneficial? Well-being and health in independent and interdependent cultures. Personality and Social Psychology Bulletin, 34, 741-754. http://dx.doi.org/10.1177/0146167208315157

Uchida, Y., Norasakkunkit, V., \& Kitayama, S. (2004). Cultural constructions of happiness: Theory and evidence. Journal of Happiness Studies, 5, 223-239. http://dx.doi.org/10.1007/s10902-004-8785-9

Uchida, Y., Takahashi, Y., \& Kawahara, K. (2011). The effect of Great East Japan earthquake for youth in Japan for their behavior and happiness. ESRI working paper, Economic and Social Research Institute, Cabinet Office, Government of Japan.

Uchino, B. N., Cacioppo, J. T., \& Kiecolt-Glaser, J. K. (1996). The relationship between social support and physiological processes: A review with emphasis on underlying mechanisms and implications for health. Psychological Bulletin, 119, 488-531. http://dx.doi.org/10.1037/0033-2909.119.3.488

Weber, M. (1920). Die protestantische ethik und der Geist des Kapitalismus. Gesammelte Aufsatze zur Religionssoziologie, I (S. 1-206), Tübingen: J.C.B. Mohr 1920.

Yuki, M., Schug, J. R., Horikawa, H., Takemura, K., Sato, K., Yokota, K., \& Kamaya, K. (2007). Development of a scale to measure perceptions of relational mobility in society. CERSS Working Paper Series No. 75. 